\title{
The Design Methods of Functional Clothing for the Elderly
}

\author{
Jinmei ZHANG, Yumin CAO*, Gengsheng CHEN \\ South China University of Technology
}

\begin{abstract}
This paper studies clothing classification, characteristics and trends by combining the basic features and needs of elderly clothing. The development status of the elderly was analyzed, the demand of the market and the "4F" design principles of costume. Then propose the design principles of the elderly function of clothing.
\end{abstract}

KEYWORD: Functional; design principles; the elderly

In a certain environment, functional clothing can effectively protect the body of human. Prevent our body from the adverse effects or injury in external environment. Along with the function of regulating and restoring the body's internal environment, health care, which can make people with clothing environment achieve the most optimal combination of state [1]. Due to the improvement of people's living standards and the increasing demands, functional requirements for the clothing will be higher, so functional clothing will become a hot research field in the future of clothing, and has incalculable market value and development potential. Development of functional clothing will show the following trends: Performance continuous optimization; function more diverse; more healthy and comfortable; expanding range of applications; increasing emphasis on the real needs of people. Because of clothing is born for people and costume design subject is "people", the elderly are among special groups in need of special attention. China has entered the aging society, the elderly apparel market has a broad space for development, and the current market is still very poor elderly apparel and more scarce for the development of functional clothing elderly. How functional clothing better services for the elderly has become the 21 st century garment industry to high-tech development is an important issue.In order to allow the elderly wearing functional clothing more comfortable, safe, design of functional clothing should pay more attention to the elderly's real needs and realistic problems, thus we can design functional clothing to better meet the elderly's needs and exceed their expectation values.

\section{THE MARKET STATUS OF FUNCTIONAL CLOTHING FOR THE ELDERLY}

Although the number of older persons in the world is so huge, development of the elderly clothing industry is unsatisfactory and the market has a serious contradiction between supply and demand. And older products on the market today, including some Haberdashery, rarely taking into account the real needs of the elderly when design the clothes with considering the function of clothing .Specialty clothing shops are few and far older; In elderly apparel sales market, at first glance, most current clothing in the market is a cloudy older, whose clothing color gray is relatively heavy, serious lack of vitality, simple obsolete style; most costume design lacks rationality. The market almost supply no functional clothing for the elderly, such as fabrics produced by special functional clothing made of new fabrics are also rare. There are many reasons for its market situation, which have a main relationship with developers, distributors and consumers. In fact, the developer is an extremely important factor. Because such a lack of awareness of people develop capabilities for the elderly clothing, so the dealer will not have sources, consumers eventually will not buy clothing; From the dealer's point of view, they think older people rarely buy clothes, and the elderly consumer awareness is not strong ; Furthermore, because the older clothing has low profits, they have no way to strive for greater profitability from the frugal old people; Finally, because the general characteristics of the elderly that he (she) physical activity are unlikely, activities range is small, sales do not go up. Various reasons commonly causes many Sellers do not want to sell clothing. Fewer 
sales people and the narrower range of choices unwittingly cause a vicious cycle results. Sellers who is specializes in old clothes are not enough, and they do not aware of the huge potential consumer market, not understand changes and needs of the elderly. In the case of dealers or developers do not pay attention, the designer is certainly much less positive, because even if the product they designed is very good, but have no way to sell. All of these reasons together led to the current market situation deserted .

\section{PHYSIOLOGICAL AND PSYCHOLOGICAL NEEDS OF THE ELDERLY CLOTHING}

Elderly older, each function senses the more serious degradation, which mainly in the following five bell degraded sensory functions. Decline of brain function, including memory capacity decline, memory capacity dislocation, thinking of slow response. Organ function decline, with increasing age, the elderly body's function of internal functions and repair work began deteriorate [2], The size, the overall external appearance of aging, wrinkles, white hair and more, generally they have different degrees of humpback phenomenon; stature, women there are two cases, one species are overweight, which is characterized by the upper body physique waist, abdominal fat and more, the coarse relatively arm , more to the foot of the fine; the other is biased very thin, but can also clearly see the skin are ruthless relaxation; and men mostly slim, in addition to the usual focus on people who exercise a relatively strong build some stature; overall apparel and more black men, blue and other dark gray-based; women jacket mostly gray color small floral pattern, there are dark, dark purple, yellowish brown color and so a little bit of pure color shirt, dark gray pants mostly partial transfer, the overall wear mostly a little thicker than the young; many older women have to go back a dorsal bag, part of the environmental protection bag fabric types; a lot of wear soft, comfortable type of sneakers or shoes.

General psychological characteristics of the elderly is that: suspicious, stubborn conservative, the pursuit of stability, nostalgia, loneliness, anxiety, psychological dependence, need to be respected, rejuvenate. The psychological dress needs of the elderly is a comfortable and fit body. Most older people in the selection of clothing, more pursuit of quality of life, therefore, to flashy clothes, he (she) prefer clothes which is comfortable and fit with their bodies, and whose value practicality can facilitate the daily life. Generous: the elderly often chooses mature and elegant style, dressed in the clothes which appears to their temper and training. Older people do not blindly follow the trend, fashion, rather like those that reflects their character and temperament of decent clothes, so let him (she) seems more confident and good taste. There is conservation in front of others. Color understated: the elderly because of living gradually become dull, ideologically more conservative and do not like too much publicity, so they generally pick the gray dress. Significantly "younger": they have significant preference for his young clothing and they are more reluctant to aging from the inside, like a significant own ruddy and clothes younger than their actual age. Significant spiritual vitality: because of declining physical fitness, lack of exercise and exercise, them seem no spirit and vitality, but they also want to give people a feel of full energy, vibrant feel, therefore, they will pick some seem full of energy clothes which seem energetic. Adapt to different occasions: after retirement the elderly put all the energy into life, so he (she) is very pursuit of quality of life, and tend to different occasions with different costumes, such as at home to wear comfortable and clean clothes to wear in the park elegant vibrant clothes, when out with friends, will be wearing decent, tasteful clothes.

\section{ELDERLY FUNCTIONAL CLOTHING DESIGN PRINCIPLES}

American Apparel Design and Engineering Scholars RF Goldman believes in the development of fashion design, and to emphasize the "Four F" principle: Feel (comfortable), Function (function fit), Fit (fit comfortably), Fashion (fashion appropriate) [3]. We can see the importance of comfort, functionality and fit of the garment design and these four principles of fashion design focus for the elderly also have similarities.

According to the basic principles of fashion design, I propose the following five design principles of functional clothing for the elderly characteristics. Functionality: it is important to consider the functional design and functional clothing should fully consider the physical needs of the elderly and Simultaneously ensure the feasibility of design; Practical: its design must meet the real needs of the elderly for modern clothing, such as practical functionality, the size of the fit, fabric, comfort, safety, etc., which are the emphasis on the elderly factors; Aesthetic: the design must meet the aesthetic point of view on the clothing of the elderly. Everyone has the beauty of the heart, so it does not mean that old people do not pursue a better visual. Functional clothing in the elderly with functional Simultaneously not lose its aesthetics, because for an ugly clothes, everyone disgust it and have no desire to wear it; Emotional: the design must meet the emotional and psychological characteristics of the elderly, although he (she) has been aging, physical condition also fade, but we should not make him 
(her) feel they have been discriminated against, because you should not hurt the elderly people's selfesteem; Overall: have an overall precisely grasp of fashion design functionality, usability, aesthetic and emotional and maintain the balance of the design. The overall style and fashion design should meet the temperament and social status of the elderly. The structure of the clothing styles, colors, materials, ideas have to plan around their overall style. Reality: The essence of design is human services, which aim to meet the needs of people in some purposeful activities .It is to improve the quality of the design and quality of human life for the purpose. Elderly functional clothing design should be able to improve the quality of life of older persons for the purpose of making clothing can better serve the elderly.

\section{ELDERLY FUNCTIONAL CLOTHING DESIGN METHODS}

Based on questionnaires and physical condition of the elderly demand for functional analysis of the conclusions of clothing, the author according to the characteristics of the elderly put forward the method of preliminary design.

\subsection{The design and analysis capabilities}

Many factors of living in the first functional aspects of the design is functional clothing designed for the elderly focus on other factors that have to be in order to achieve the purpose of the function and collaboration .Functionality required by elderly population ages has the other side of the special exhibit .For its functional design, the elderly can be divided into three levels to specific analysis. 1) Daily life can take care of the elderly. Life can take care of the elderly are also two cases, one is relatively good physical condition with basically a rare problem, one is that there are some problems, but does not affect the life of self-care. Relatively good physical condition for the elderly, designed only to consider health care functions and supplemented by other functions when necessary; For occasional physical condition but does not affect the daily living of the elderly, we also consider the need for care and protection features clothing. 2) The appropriate daily life of the elderly in need of help. Under normal circumstances, the proper life of the elderly in need of help, there is some inconvenience on their body, so clothing design features situation where you want to be able to play the role of adjuvant therapy, but health care is still a prerequisite for the function. 3) Daily life do not take care of the elderly. Designed to facilitate the others who want to wear for the elderly. Functional should be designed to assist the elderly to be for the purpose of restoring good health. Of course, no matter what the situation should be in specific conditions, because everyone's circumstances are different from everyone else, so the specific needs inevitably vary, therefore, we must specifically design its functionality depending on the circumstances.

\subsection{Fabric selection and adoption}

For the choice of fabric, firstly, to consider it for the realization of the function of clothing is viable and whether it beneficial to the function of the play, but also to ensure the harmonization of fabrics and clothing styles, and on this basis, to select a suitable fabric according to the physiological changes of the elderly. In winter, the elderly clothing should have a stronger protection sex, with the decline of bodily functions, blood circulation and metabolism slows down, plus the usual exercise less and not harder, less heat is generated, resulting in the elderly relatively cold, so, warm winter clothing for the elderly must be good, has no sense of restraint and pressure, does not affect blood circulation and hand, foot and activities of the elderly. In summer, the clothing should light, thin, soft, feel good, breathable moisture absorption, and no stimulation, health care of fabrics. Especially with health care function of the fabric, is widely used in recent years. Health care fabric fiber which contains more substances has a medical effect. The wearer during wear in health care can slowly release substances for certain diseases, which can play a certain effect function. In the summer, many people now prefer hemp fabrics, because hemp fabrics are more natural plant fiber cloth, good moisture absorption, heat quickly, cool, and has antibacterial health functions. Most of the elderly, especially the aged elderly who have less wear bras underwear, they generally choose summer coat with a vest, because it is directly in contact with the skin of the elderly. The choice of the fabric is suitable for cotton fabrics and soft on the skin permeability is strong. For apparel fabrics, whether it is winter or summer, garments should be beneficial to the realization of the function with the right mix of style, accord with the temperament characteristic of old people, meet the needs of the elderly and way of life.

\subsection{Design and analysis of the style}

In order to make a wide range of applications and use objects pan, style of many functional clothing design generally is more popular, rarely conceived for special populations and nor fully taken into account the differences of people, such as a hospital gown, the elderly, young people, children and women are the same men clothing. Not blue and white stripe is black and white stripes, its style and 
fabric are the same, which fails to adapt to the characteristics of different people.

Elderly functional clothing, key of its structure design style for the realization of the function of clothing firstly, moreover is according to the physiological and psychological characteristics of old people. First, for the elderly, upside down separate structure than Siamese more appropriate; Secondly, the elderly tend front cardigan coat, because their shoulders and arm joints are not flexible and when they lift arm, they have the certain difficulty. Especially in the winter, so design of hedging tight sleeve does not fit; Third, to meet the special stature characteristics of the elderly, especially elderly women body, who have abdomen and upper arm, so tight clothing easily affect vascular compression blood circulation and khan gas distribution is unfavorable to the body. Therefore, the jacket should have a certain amount of easing, but also should have a certain fit, which should try to make the shape change and formation of the body up, measurable beautification body; Fourth, the bottoms of trousers crotch to be long enough. Its waist head should be high enough, because too tight will make lower body uncomfortable, and not show a channel when crouching, because old people don't think this is a kind of culture phenomenon; Fifth, on the design of the details, clothing pocket, had better take things convenient to the old, but unfavorable and overmuch. Sixth, on the adornment gimmick, give priority to with ornament, exquisite moderately, and should not be too much decoration.

On the design of the style, it should arouse our special functional clothing, also reflect that the clothing is practical, easy to wear off, the convenience of daily life activities, fully show the merits of the elderly and hide their shortcomings. The overall style is given priority to with concise and easy, accord with the old grave identity and social status.

\subsection{Color selection and analysis}

The contrast of the old products on color should not be too strong. most elderly people tend to be soft, low lightness and low purity of clothing color, which has to do with the elderly and gentle character. In tonal on, old people tend to warm tones, especially for women, which is associated with the psychological hint of color to produce, because warm color attune give a person the sense of happiness and warmth, which conform to the psychological characteristic of elderly people that they are afraid of loneliness. However, because of the influence of the children and friends, now a lot of the old concept of fashion is changing, he (she) can accept the expression of personality. From the point of view of psychology, bright colors often give a person spirit and happy hint, which not only helps to cultivate a good mood, also beneficial to the health of the elderly. Therefore, if collocation is proper, the elderly can moderately present clothing color beautiful side, also can make the elderly aged skin look young and spirit, which also accord with the old "younger" psychological characteristics of dress.

\section{CONCLUSION}

Overview the present development status and prospects of functional clothing, parse the elderly of functional clothing market demand and the status quo of the on-the-spot investigation of the existing market. Through carry on the investigation of research methods for modern health of the elderly, the demand to the clothing was summarized and analyzed.According to the characteristics of the elderly in the design of functional clothing, puts forward the design follow the functional, practical, aesthetic, emotional, five principles of integrity. Finally established the old design method of functional clothing theory and explore research on the application of functional clothing in the old principle.

\section{REFERENCES}

[1] Du Juanjuan development trend of functional clothing and recommendations. Technology Information, 2010 (27): 246-246.

[2] Jia temple and, by the ability to love what disease the elderly. Beijing: People's Medical Publishing House, 2012: 11-18.

[3] STEVEN Goldman, ROGER Nagel, KENNTH preiss Sgile competitors and virtual organizations. New York: Van Nostrond Reinhold, 1995.

[4] YASUDA H, MIYAMA M. Dynamic water vapour and heat transfer through layered fabrics: Part 2: Effect of chemical nature of fibers. Textile Research Journal, 1992, 62(4): 55-58.

[5] World Population Aging 1950-2050. United Nations, New York, 2002.

[6] Grabois M. Management of chronic low back pain. Am J Phys Med Rehabil, 2005, 84(3): S29-41.

[7] Laurin C. A. Cervical traction at home. Union Med Can, 1966, 95(1): 80-3.

[8] Zhang Kexin. Clothing materials science. Shijiazhuang: hebei fine arts publishing house, 2005. 6.

[9] Older product design analysis and characteristics of the study. Journal of design, 2014 (2): 59-60.

[10] Li Shuying. Old people's psychological, physiological characteristics and the adjustment. Chinese journal of clinical care, 2004, 7 (6): 479-480. 